\title{
Distribuição vertical e horizontal de temperaturas do ar em ambientes protegidos
}

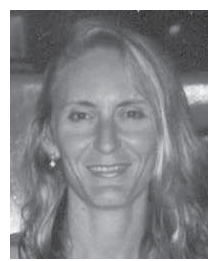

Raquel A. Furlan ${ }^{1} \&$ Marcos V. Folegatti ${ }^{2}$

1 SEAGRI/CE. Ed. SEAD, Térreo. CEP 60839-900, Fortaleza, CE. Fone: (85) 488-2573, Fax: (85) 488-2567. E-mail: raquel furlan@bol.com.br (Foto)

2 ESALQ/USP. E-mail: mvfolega@carpa.ciagri.usp.br

Protocolo $133-27 / 10 / 2000$

Resumo: Este trabalho foi realizado na área experimental do Departamento de Engenharia Rural da Escola Superior de Agricultura "Luiz de Queiroz", Piracicaba, SP, Brasil, em dois ambientes protegidos construídos no sentido leste-oeste, com área total de $112 \mathrm{~m}^{2}$ e coberto com plástico (150 micra), tratado contra raios ultravioleta. Para caracterizar a distribuição espacial da temperatura do ar no ambiente protegido, instalaram-se termopares (cobre-constantã) formando malhas, com espaçamento horizontal entre eles de 3,0 m e nas alturas de 0,5, 1,0, 2,0, 3,0 e 4,0 m em relação ao solo. Os dados foram armazenados a cada $15 \mathrm{~min}$ por sistemas automáticos de aquisição de dados nos ambientes protegidos. O sistema de nebulização constituiu-se de duas linhas com 70 bocais totais, instalados a uma altura de 3,0 m, utilizando-se uma pressão de trabalho de $200 \mathrm{kPa}$. A nebulização não afetou o gradiente vertical de temperatura, que manteve a tendência de aumento de temperatura com a altura, em relação ao nível do solo, enquanto o efeito na redução de temperatura pelo sistema de nebulização somente foi eficaz durante a realização da mesma. Para a representação da distribuição espacial de temperatura do ar no ambiente protegido nos diferentes níveis de altura, construiu-se superfícies isotérmicas a partir dos resultados. Verifica-se que a nebulização apresentou maior efeito na homogeneização da distribuição de temperatura no ambiente protegido no nível referente a 2,0 m de altura, em relação ao solo.

Palavras-chave: isotermas, nebulização, estufa, manejo de temperatura do ar, plasticultura, abertura de cortinas laterais

\section{Vertical and horizontal distribution of air temperature in a plastic greenhouse}

\begin{abstract}
This work was conducted in the experimental area of the Department of Rural Engineering of "Escola Superior de Agricultura Luiz de Queiroz", University of São Paulo, Piracicaba, São Paulo, Brazil. Two greenhouses were installed in the east-west direction, with $6.4 \mathrm{~m}$ of width, $17.5 \mathrm{~m}$ of length and $3.0 \mathrm{~m}$ high, with total area of $112 \mathrm{~m}^{2}$; covered by plastic of 150 micra thickness, treated against ultra violet rays. To characterize the space distribution of the air temperature inside the greenhouse atmosphere, thermo couples of (copper-constantan) were installed, forming a grid spaced $3.0 \mathrm{~m}$ horizontally, at the heights of $0.5,1.0,2.0,3.0$ and 4.0 $\mathrm{m}$ above the soil. The data were stored every $15 \mathrm{~min}$ by a system of data acquisition. The fog system constituted of two lines with 70 foggers, installed at $3.0 \mathrm{~m}$ height and operating at a pressure of $20 \mathrm{kPa}$. The fog system did not affect the vertical temperature gradient, maintaining the tendency of increase of the air temperature with the height in relation to the soil level. While the effect of fog system to decrease the air temperature was effective when the system was on. The representation of the air temperature distribution in space inside the greenhouse at different height levels was done by isotherm surfaces. It was verified that the fog system had the highest effect in the homogenization of the air temperature distribution inside the greenhouse at the height of $2.0 \mathrm{~m}$ from the soil.
\end{abstract}

Key words: isotherms, fog system, greenhouse, air temperature management, plasticulture, lateral opening of curtains 


\section{INTRODUÇ̃̃O}

Nos ambientes protegidos, a elevação de temperatura do ar é o principal problema de manejo em regiões de climas tropicais e subtropicais com verões quentes. A redução de temperatura é fundamental para se obter bom controle do clima que favoreça a performance da cultura e condições agradáveis de trabalho para as pessoas. Uma das mais eficientes maneiras de se reduzir a diferença entre a temperatura do ar no ambiente protegido e a externa, é melhorar a ventilação (Oca et al., 1999); outra seria através do sistema de resfriamento por evaporação da água, que reduz a temperatura no ambiente protegido devido à troca do calor sensível por calor latente, o que aumentaria a quantidade de vapor de água (Montero et al., 1990). Andriolo (1999) concorda que a redução da temperatura do ar excessivamente elevada pode ser feita pela ventilação ou pela nebulização, sendo a primeira mais fácil de ser utilizada, a do tipo estática, depende basicamente da diferença de pressão entre o ar localizado no interior e no exterior do ambiente protegido, enquanto a nebulização, para diminuir a temperatura do ar, depende do déficit de saturação de vapor do ar. Esta técnica será tão mais eficiente quanto maior for o déficit de saturação, porém, quando a umidade do ar já está com valores elevados, a nebulização proporciona resultados pouco satisfatórios, razão pela qual é mais conveniente empregar-se a ventilação e a nebulização, simultaneamente; entretanto, quando a nebulização é realizada de maneira incorreta, pode provocar o molhamento das plantas, aumentando o risco de ocorrência de moléstias (Andriolo, 1999).

Com o objetivo de melhor visualizar o efeito dos sistemas de redução de temperatura empregados, Baeten et al. (1985) propuseram um método para cálculo de distribuição de temperatura por meio de vários pontos de amostragem em ambiente protegido e representação por meio de isotermas. Este método foi aplicado em planos horizontais e em diferentes alturas em todo o ambiente protegido e a distribuição de temperatura foi apresentada e discutida, permitindo obter-se melhor visão da flutuação de temperatura no ambiente protegido.

Triki et al. (1984) compararam quatro diferentes sistemas de aeração e sua influência na distribuição de temperatura, através de isotermas, cujas temperaturas foram coletadas a $1,5 \mathrm{~m}$ de altura em relação ao solo. Eles observaram que a distribuição de temperatura do ar foi mais homogênea nos ambientes protegidos onde a aeração lateral foi combinada com aeração pelo teto. $\mathrm{O}$ uso de dois ventiladores resultou em distribuição de temperatura do ar muito heterogênea, com acúmulo de calor no centro do ambiente protegido.

Buriol et al. (1997) determinaram o gradiente térmico vertical no interior de ambientes protegidos com filmes plásticos, medindo a temperatura com sensores instalados nos níveis de 0,2, 0,6 e 2,0 m acima do nível do solo, sobre cultura da alface e do tomate. Os resultados mostraram que, no interior dos ambientes protegidos e durante o período diurno, ocorreu aumento da temperatura do ar com a altura, enquanto no período noturno não se verificou, como se esperava, a ocorrência de inversão térmica. Esta variação foi observada tanto na cultura de porte baixo (alface) como na cultura de maior porte (tomate).
O presente trabalho foi realizado com o objetivo de se caracterizar e avaliar um sistema de resfriamento da temperatura do ar por nebulização no interior do ambiente protegido com solo $\mathrm{nu}$, através de isotermas e do perfil vertical de temperatura do ar.

\section{MATERIAL E MÉTODOS}

O presente trabalho foi realizado na área experimental do Departamento de Engenharia Rural, da Escola Superior de Agricultura "Luiz de Queiroz", situada no município de Piracicaba, SP, cujas coordenadas geográficas são: latitude $22^{\circ} 42^{\prime} \mathrm{S}$, Longitude $47^{\circ} 38^{\prime} \mathrm{W}$ e altitude de $570 \mathrm{~m}$. Segundo a classificação climática de Köppen, Piracicaba possui clima Cwa, ou seja, subtropical úmido, com estiagem no inverno e temperatura média no mês mais frio inferior a $18^{\circ} \mathrm{C}$ e no mês mais quente, superior a $22^{\circ} \mathrm{C}$. O solo do local do experimento foi classificado como Terra Roxa Estruturada (Alfisol). Dois ambientes protegidos similares foram instalados no sentido leste-oeste, tendo $6,4 \mathrm{~m}$ de largura por $17,5 \mathrm{~m}$ de comprimento, pé direito de $3,0 \mathrm{~m}$, espessura do plástico de 150 micra, filmes plásticos em PVC SANSUY, janelas zenitais de abertura longitudinal de $1,50 \mathrm{~m}$ de largura e comprimento de $17,5 \mathrm{~m}$, fechada com tela de malha (30\%) e janelas laterais fechadas com sombrite a $60 \%$ e plástico removível. Uma amostragem sistemática com termopares constituídos de fios de cobre e constantã regularmente distribuídos nas três direções do espaço (x, y e z) foi realizada para se obter as isotermas. Foram instalados termopares com espaçamento horizontal de $3,0 \mathrm{~m}$ e nas alturas de 0,5, 1,0,2,0,3,0 e 4,0 m em relação ao nível do solo.

$\mathrm{Na}$ Figura 1A está representada, esquematicamente, a localização das 18 estacas de sustentação dos termopares na direção horizontal e na Figura 1B os termopares na direção vertical, nas diferentes alturas.

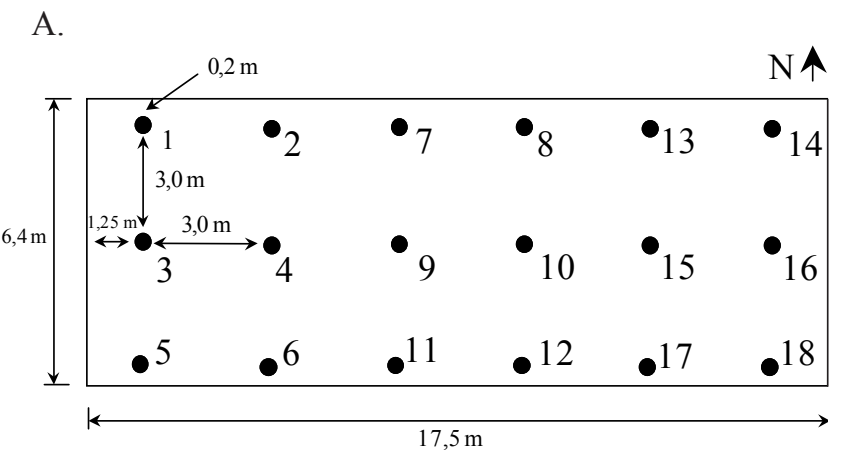

B.

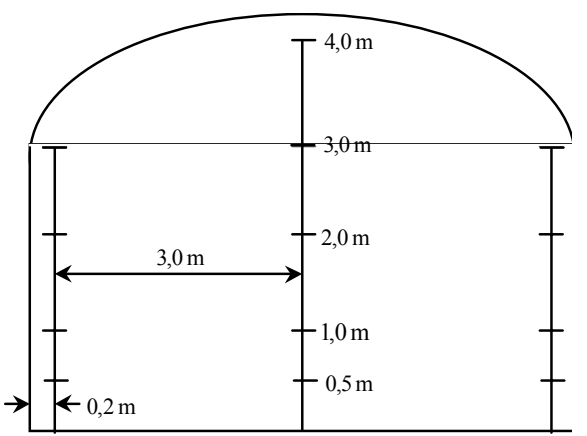

Figura 1. Representação esquemática da localização das estacas sustentadoras dos termopares na direção horizontal (A) e na direção vertical (B) 
Os sistemas de aquisição de dados utilizados nos ambientes protegidos foram os modelos CR10, Campbell Scientific, com dois multiplexadores, e o CR7, da mesma empresa, programados para efetuarem leituras a cada segundo e médias a cada $15 \mathrm{~min}$.

Para determinar o gradiente térmico vertical no ambiente protegido, utilizou-se a média de 4 valores de temperatura do ar para cada uma das 5 alturas acima do nível do solo $(0,5 ; 1,0 ; 2,0$; 3,0 e 4,0 m) nos dias 4/11/1999 e 1/12/1999. As 4 repetições estavam distribuídas e localizadas na parte central do ambiente protegido, nas estacas 4, 9, 10 e 15 (Fig. 1A) as quais continham um termopar em cada uma das alturas acima citadas. Para análise da distribuição horizontal de temperatura, utilizaram-se dados coletados nos dias já citados, obtidos em 78 pontos de amostragem, os quais formaram a malha utilizada na caracterização das isotermas. Para análise no trabalho foram escolhidos e utilizados os termopares correspondentes às alturas de 0,5 e 2,0 m em relação ao nível do solo, sendo que, em cada altura considerada, foram empregados 18 pontos de amostragem. Esses dias foram escolhidos por apresentarem condições climáticas semelhantes e a mesma altura de abertura de cortina lateral (1,0 $\mathrm{m}$ de altura em relação ao nível do solo). Um dos ambientes protegidos permaneceu com as cortinas fechadas e sem nebulização (testemunha) e, no outro, foram abertas as cortinas e nebulizado.

O sistema de nebulização era constituído de duas linhas com 70 bocais (DAN FOGGER 7800, Dan Sprinkler) com densidade de $1,6 \mathrm{~m}^{2}$ por bico nebulizador, instalados a uma altura de $3,0 \mathrm{~m}$. A pressão de serviço dos bocais foi de $200 \mathrm{kPa}$, enquanto uma representação gráfica simples das temperaturas do ar coletadas, consistiu em se plotar cada dado observado e construir superfícies isotérmicas a partir deles.

\section{RESULTADOS E DISCUSSÃO}

No dia 4/11/1999, no ambiente protegido manejado, as cortinas laterais foram abertas a $1,0 \mathrm{~m}$ de altura em relação ao nível do solo e acionado o sistema de nebulização às $9 \mathrm{~h}$. Às $15 \mathrm{~h}$, fecharam-se as cortinas e se desligou o nebulizador. A temperatura média do ar neste intervalo foi de $47,1^{\circ} \mathrm{C}$ no ambiente testemunha e de $33,1^{\circ} \mathrm{C}$ no ambiente com as cortinas abertas e nebulizado. No dia 1/12/1999, a cortina zenital foi aberta às $10 \mathrm{~h} 45 \mathrm{~min}$ e às $12 \mathrm{~h}$, as cortinas laterais do ambiente foram abertas a 1,0 $\mathrm{m}$ de altura em relação ao nível do solo. $\mathrm{O}$ acionamento do nebulizador iniciou-se às $12 \mathrm{~h} 45 \mathrm{~min}$ e às $14 \mathrm{~h} 30 \mathrm{~min}$ foi desligado. A temperatura média do ar do ambiente protegido testemunha durante o manejo, foi de $48,2{ }^{\circ} \mathrm{C}$ e no ambiente protegido com cortinas abertas e nebulização, foi de $36,8^{\circ} \mathrm{C}$.

A Figura 2A apresenta o perfil de distribuição de temperatura no dia 4/11/1999, no ambiente protegido onde ocorreu abertura de cortinas laterais a 1,0 m de altura em relação ao nível do solo e nebulização, enquanto a Figura 2B mostra o perfil de temperatura no ambiente protegido controle. Às 9h, representa o horário anterior ao manejo das cortinas e nebulização, quando os dois ambientes protegidos apresentaram condições de distribuição de temperatura muito semelhantes, com temperaturas próximas a $40,0{ }^{\circ} \mathrm{C}$ ao nível de $0,5 \mathrm{~m}$ de altura e ao redor de $44,0^{\circ} \mathrm{C}$, em nível de $4,0 \mathrm{~m}$. No perfil determinado às $12 \mathrm{~h} 30 \mathrm{~min}$ na Figura $2 \mathrm{~A}$, em comparação com a
A.

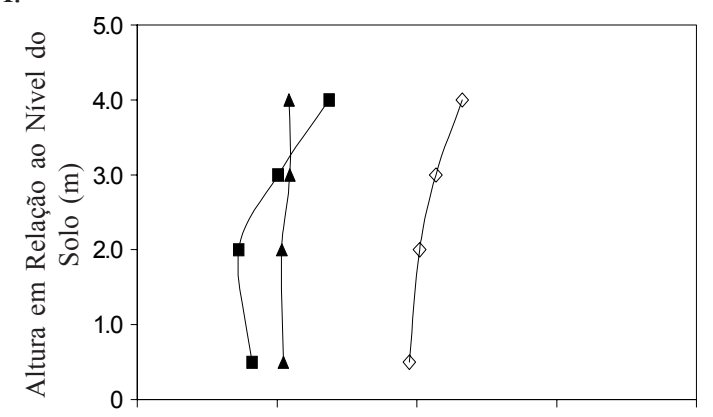

B.

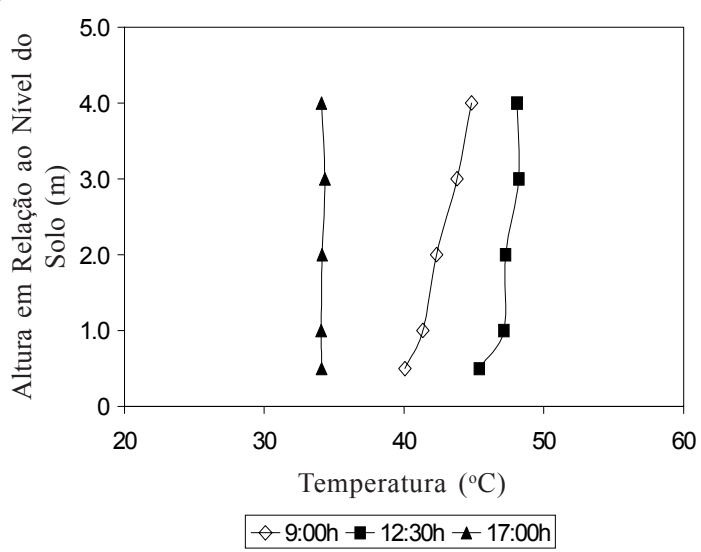

Figura 2. Perfil vertical de temperatura do ar no ambiente protegido com abertura de cortinas laterais e nebulização (A) e ambiente protegido testemunha (B), antes da abertura e nebulização $(9 \mathrm{~h})$, durante (12h30 min) e duas horas após o término da nebulização (17 h) no dia 4/11/1999

Figura 2B, observou-se claramente o efeito da redução de temperatura do ar pela nebulização e ventilação natural; nesse horário, as cortinas foram abertas e a nebulização acionada, reduzindo a temperatura média do ar do ambiente em cerca de $17,0^{\circ} \mathrm{C}$ (com valores médios de temperatura no perfil de $47,2^{\circ} \mathrm{C}$ no ambiente protegido testemunha e $29,8^{\circ} \mathrm{C}$ no ambiente com nebulização e ventilação natural). $\mathrm{O}$ perfil das $17 \mathrm{~h}$ (Fig. 2A e B) representa o período após o encerramento da nebulização e o fechamento das cortinas. Nesse horário, houve distribuição homogênea de temperatura em todo o perfil, porém com valores médios de $30,5^{\circ} \mathrm{C}$ no ambiente protegido onde ocorreram nebulização e ventilação natural $\mathrm{e} 34,0^{\circ} \mathrm{C}$ no ambiente controle, evidenciando o efeito de redução de temperatura do ar pela nebulização, mesmo após o seu encerramento. Nesta hora do dia, o aquecimento da cobertura plástica pela radiação solar e a transmissão de calor através desta para o ar do interior do ambiente protegido, passam a ser mínimos, não interferindo na temperatura do ar nem causando gradiente de temperatura como ocorre nos períodos mais quentes do dia. $\mathrm{O}$ aumento da temperatura do ar com a altura também foi verificado por Buriol et al. (1997) sendo o gradiente de temperatura do ar maior nos horários compreendidos entre 11 e $14 \mathrm{~h}$.

Na Figura 3 encontram-se os perfis verticais de distribuição de temperatura do ar no ambiente protegido, durante a nebulização. O efeito da nebulização na redução da temperatura do ar no ambiente protegido, independente do horário analisado, ocorreu principalmente de 0,5 a $2,0 \mathrm{~m}$, sendo que seu efeito diminuiu à medida que se aproximou dos nebulizadores instalados a 3,0 m de altura em relação ao nível do solo. A 4,0 m 


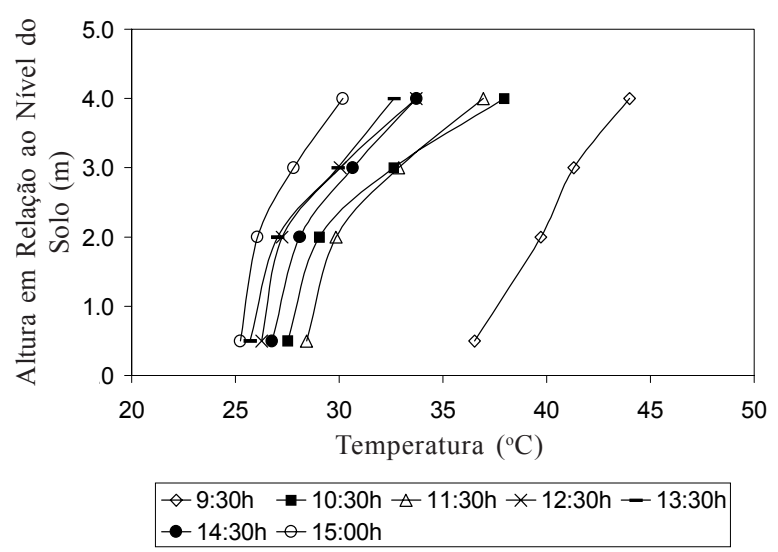

Figura 3. Distribuição vertical de temperatura do ar durante o período em que ocorreu a nebulização (das $9 \mathrm{~h} 30 \mathrm{~min}$ às $15 \mathrm{~h}$ ) no dia 4/11/1999

de altura, a temperatura do ar se manteve mais elevada, quando comparada com as demais alturas, durante todo o período com nebulização. A variação de temperatura entre o ponto de menor temperatura ( $0,5 \mathrm{~m}$ de altura em relação ao nível do solo) e maior temperatura (4,0 $\mathrm{m}$ de altura em relação ao nível do solo) foi de $5,0^{\circ} \mathrm{C}$ (às $15 \mathrm{~h}$ ) e $10,4^{\circ} \mathrm{C}$ (às $10 \mathrm{~h} 30 \mathrm{~min}$ ). As maiores diferenças de temperatura do ar entre o nível de 0,5 e 4,0 m ocorreram nos períodos mais quentes do dia, devido ao maior aquecimento da cobertura plástica. A nebulização reduziu a temperatura do ar a valores menores que os obtidos no ambiente testemunha, sendo o efeito da nebulização mais pronunciado de 0,5 a 2,0 m de altura.

A Figura 4 apresenta as isotermas a $0,5 \mathrm{~m}$ de altura em relação ao nível do solo, no dia 4/11/1999, para o ambiente protegido com nebulização e abertura de cortinas laterais e o ambiente protegido controle para diferentes horários.

Às 9h (Fig. 4A e D) a variação de temperatura nos diferentes pontos de amostragem nos ambientes protegidos não teve grande amplitude, com variação de 1,5 a $2,5^{\circ} \mathrm{C}$ no ambiente protegido com nebulização e ventilação natural e o ambiente controle, respectivamente. $\mathrm{O}$ ambiente protegido testemunha

A.

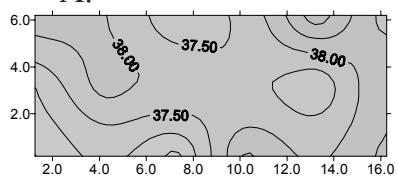

B.

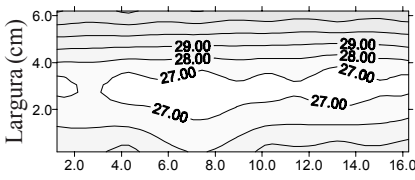

C.

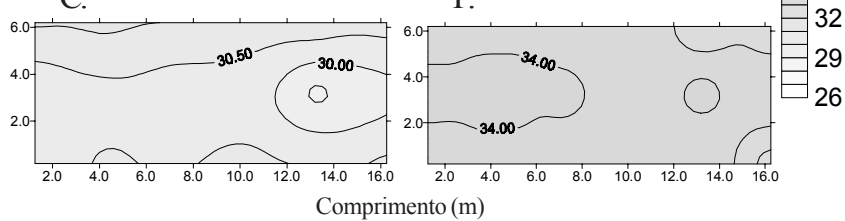

Figura 4. Distribuição de temperatura do ar no ambiente protegido com nebulização e abertura de cortinas laterais (A, B e C) e o ambiente protegido controle $(\mathrm{D}, \mathrm{E}$ e F) para os horários das $9 \mathrm{~h}$ (A e D), $12 \mathrm{~h} 30 \mathrm{~min}$ (B e E), e $17 \mathrm{~h}(\mathrm{C} \mathrm{e} \mathrm{F})$ a $0,5 \mathrm{~m}$ de altura em relação ao nível do solo no dia 4/11/1999
(Fig. 4D) imediatamente após a abertura das cortinas laterais e nebulização (Fig. 4A) já se encontrava com cerca de $1,0^{\circ} \mathrm{C}$ de temperatura do ar acima da temperatura do ar no ambiente protegido com abertura de cortinas e nebulização. Num dos períodos de maior elevação de temperatura do ar no ambiente protegido (12h30 min) constatou-se efeito da nebulização e ventilação natural na redução da temperatura do ar (Fig. 4B e E). A temperatura do ar no ambiente protegido controle a $0,5 \mathrm{~m}$ de altura em relação ao nível do solo (Fig. 4E) variou de 43,5 a $46,5^{\circ} \mathrm{C}$, enquanto no ambiente protegido com nebulização e ventilação natural (Fig. 4B) variou de 27 a $31{ }^{\circ} \mathrm{C}$, reduzindo cerca de $34,5 \%$ da temperatura do ar (com temperaturas do ar médias a $0,5 \mathrm{~m}$ de 44,6 e $29,2{ }^{\circ} \mathrm{C}$, respectivamente).

No ambiente protegido nebulizado (Fig. 4B) as isotermas divergiram do centro e longitudinalmente do ambiente protegido formando uma zona de redução de temperatura do ar por efeito do alcance dos nebulizadores, que não atingiram as laterais, ou pela entrada de ar mais seco vindo do ambiente externo.

Nas Figuras $4 \mathrm{C}$ e F (às $17 \mathrm{~h}$ ) estão representadas as distribuições horizontais de temperatura do ar no ambiente protegido após o término da nebulização e após o fechamento das cortinas. A distribuição de temperatura do ar no ambiente protegido nebulizado (Fig. 4C) apresentou temperaturas inferiores às do ambiente protegido controle (Fig. 4F) variando de 30,0 a $31,0{ }^{\circ} \mathrm{C}$ e 33,5 a $34,0{ }^{\circ} \mathrm{C}$ (cerca de $9,5 \%$ de redução) com temperaturas médias de 30,5 e $33,7{ }^{\circ} \mathrm{C}$, respectivamente, mostrando a influência da nebulização e ventilação natural do ambiente na redução da temperatura do ar e, ainda, o efeito após sua interrupção. Ocorreu elevação da temperatura do ar do ambiente protegido após a interrupção da nebulização e ventilação natural de cerca de 4,5\%. Entretanto, a temperatura do ar neste ambiente se manteve abaixo da temperatura do ar do ambiente controle, conforme visto anteriormente.

De acordo com Fang (1995), em regiões de umidade relativa alta, o manejo de ambiente protegido adotado é o de se utilizar a ventilação para manter a renovação de ar. Al-Jamal (1994) constatou que, para condições de mesma umidade relativa, ocorreu maior resfriamento por nebulização quando a taxa de renovação de ar foi maior.

A Figura 5 apresenta as isotermas a 2,0 $\mathrm{m}$ de altura em relação ao nível do solo no dia 4/11/1999 para o ambiente protegido com nebulização e abertura de cortinas laterais e o ambiente protegido controle para os diferentes horários.

A 2,0 $\mathrm{m}$ de altura em relação ao nível do solo tem-se praticamente a mesma situação verificada a $0,5 \mathrm{~m}$, porém com pequena elevação da temperatura do ar para os horários das $9 \mathrm{~h}$ e $12 \mathrm{~h} 30 \mathrm{~min}$. A temperatura do ar no ambiente protegido com nebulização e ventilação natural às $9 \mathrm{~h}$ (Fig. 5A) variou de 40,0 a $42,0{ }^{\circ} \mathrm{C}$ e de 42,5 a $43,5{ }^{\circ} \mathrm{C}$ no ambiente protegido controle (Fig. 5D), com médias de temperatura do ar de 40,9 e $42,8^{\circ} \mathrm{C}$, respectivamente. Às $12 \mathrm{~h} 30 \mathrm{~min}$ a variação foi de 28,0 a $32,0^{\circ} \mathrm{C}$ no ambiente protegido com nebulização e ventilação natural e de 46,0 a $47,0^{\circ} \mathrm{C}$ no ambiente controle, com médias de 30,7 e $47,1^{\circ} \mathrm{C}$, respectivamente, reduzindo a temperatura em $34,8 \%$. Às $17 \mathrm{~h}$, entretanto, não houve aumento de temperatura do ar com a altura ficando com distribuição de temperatura do ar e valores muito próximos das observadas a $0,5 \mathrm{~m}$, conforme pôde ser também observado na Figura 2. 
A.

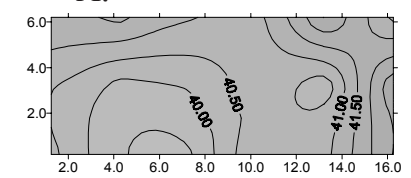

B.

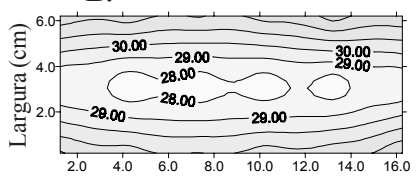

C.

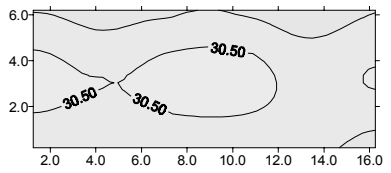

Comprimento $(\mathrm{m})$
D.

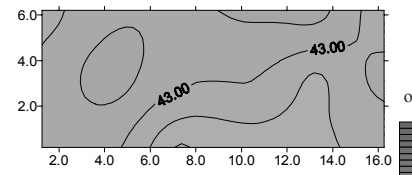

E.

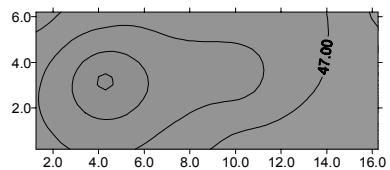

F.

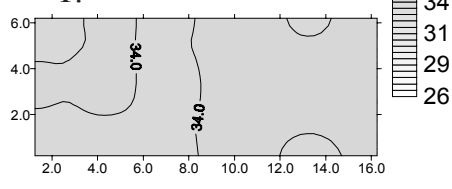

Figura 5. Distribuição de temperatura do ar no ambiente protegido com nebulização e abertura de cortinas laterais (A, B e C) e o ambiente protegido controle $(\mathrm{D}, \mathrm{E}$ e F) para os horários das $9 \mathrm{~h}$ (A e D), $12 \mathrm{~h} 30 \mathrm{~min}(\mathrm{~B} \mathrm{e} \mathrm{E}), \mathrm{e} 17 \mathrm{~h}(\mathrm{C} \mathrm{e} \mathrm{F})$, à 2,0 $\mathrm{m}$ de altura em relação ao nível do solo no dia 4/11/1999

A nebulização resultou em distribuição de temperatura do ar mais homogênea, principalmente abaixo do nível dos nebulizadores.

A Figura 6A representa o perfil de distribuição de temperatura no dia 1/12/1999, no ambiente protegido onde ocorreu abertura de cortinas zenitais e laterais a $1,0 \mathrm{~m}$ de altura em relação ao nível do solo e nebulização e a Figura 6B apresenta o perfil de temperatura no ambiente protegido controle.

$\mathrm{O}$ perfil correspondente às $10 \mathrm{~h} 30 \mathrm{~min}$ representa o horário anterior ao manejo das cortinas e nebulização. Nesse horário, os dois ambientes protegidos apresentam condições de distribuição de temperatura muito semelhantes com temperaturas próximas a $45,0^{\circ} \mathrm{C}$ ao nível de $0,5 \mathrm{~m}$ de altura em torno de $52,0^{\circ} \mathrm{C}$ ao nível de $4,0 \mathrm{~m}$. No perfil representado pelo horário das $11 \mathrm{~h} 30$ min nas Figuras 6A e B nota-se o efeito da redução de temperatura do ar pela abertura da cortina zenital. Na Figura $6 \mathrm{~A}$ o perfil vertical de temperatura é muito variável, porém com temperaturas em declínio nas proximidades da saída de ar pela janela zenital, chegando a $41,0^{\circ} \mathrm{C}$ a $4,0 \mathrm{~m}$ de altura em relação ao nível do solo e $42,5^{\circ} \mathrm{C}$ a $0,5 \mathrm{~m}$. A temperatura média para este perfil foi de $43,3{ }^{\circ} \mathrm{C}$. Já no ambiente protegido controle (Fig. 6B) a temperatura média do perfil chegou a $50,5^{\circ} \mathrm{C}$. A $0,5 \mathrm{~m}$ a temperatura foi de $47,6{ }^{\circ} \mathrm{C}$ e a $4,0 \mathrm{~m}$ de $55,4^{\circ} \mathrm{C}$. Em média, a redução de temperatura foi cerca de $7,0^{\circ} \mathrm{C}$.

$\mathrm{O}$ perfil correspondente às $12 \mathrm{~h} 15 \mathrm{~min}$ representa o perfil vertical de temperatura após abertura da cortina lateral a 1,0 m de altura em relação ao nível do solo. Nos dois ambientes, este perfil vertical de temperatura do ar segue a mesma tendência do perfil ocorrido às $11 \mathrm{~h} 30 \mathrm{~min}$, porém com temperaturas do ar inferiores no ambiente protegido com cortinas zenitais e laterais abertas (Fig. 6A) e temperaturas superiores no ambiente protegido controle (Fig. 6B). Assim, enquanto a temperatura do ar aumentou no ambiente protegido controle, no outro ambiente a temperatura diminuiu após a abertura da cortina lateral. A $0,5 \mathrm{~m}$ de altura em relação ao nível do solo a temperatura no ambiente protegido controle foi de $48,9^{\circ} \mathrm{C}$ e no ambiente protegido com as cortinas abertas foi de $40,6^{\circ} \mathrm{C}$. A $4,0 \mathrm{~m}$ de altura em relação ao nível do solo a temperatura do ar
A.

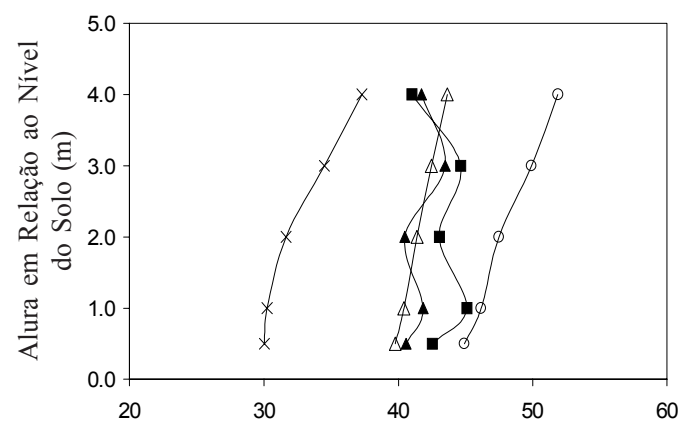

B.

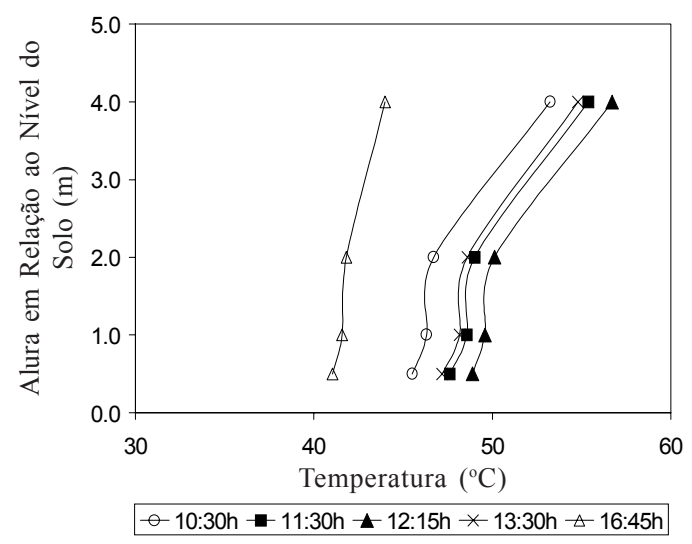

Figura 6. Perfil vertical de temperatura no ambiente protegido com abertura de cortinas (laterais e zenital) e nebulização (A) e ambiente protegido testemunha (B), antes da abertura da cortina zenital (10h30 min), após a abertura da cortina zenital (11h30 min), após a abertura das cortinas laterais a 1,0 $\mathrm{m}$ de altura em relação ao nível do solo (12h15 min), durante a nebulização (13h30 min) e após o término da nebulização (16h45 min) durante o dia 1/12/1999

atingiu $56,7^{\circ} \mathrm{C}$ no ambiente protegido controle e $41,7^{\circ} \mathrm{C}$ no ambiente protegido com ventilação natural. A média para o perfil do ambiente protegido controle foi de $51,33{ }^{\circ} \mathrm{C}$ enquanto para o ambiente protegido com ventilação natural foi de $41,6^{\circ} \mathrm{C}$, representando uma diferença de cerca de 19,0\%.

No perfil representado pelo horário das $13 \mathrm{~h} 30 \mathrm{~min}$ as cortinas foram abertas e a nebulização acionada reduzindo a temperatura média do ar do ambiente em cerca de $17,0^{\circ} \mathrm{C}$ (com valores médios de temperatura no perfil de $49,7^{\circ} \mathrm{C}$ no ambiente protegido testemunha e $32,7^{\circ} \mathrm{C}$ no ambiente com nebulização e ventilação natural, ou seja, diferença de 34\%). Neste horário, na Figura 6B, o perfil vertical de temperatura do ambiente protegido controle apresentou maior uniformidade com temperaturas variando de $47,2^{\circ} \mathrm{C}$ para o nível de $0,5 \mathrm{~m}$ e de $54,8{ }^{\circ} \mathrm{C}$ para o nível de $4,0 \mathrm{~m}$ (cerca de 14\%). No ambiente protegido com cortinas abertas e nebulização (Fig. 6A) verificou-se maior redução de temperatura do ar no ambiente de 0,5 a 2,0 m, por efeito da nebulização. As temperaturas variaram de $30,0^{\circ} \mathrm{C}$ a $0,5 \mathrm{~m}$ de altura em relação ao nível do solo e $37,3^{\circ} \mathrm{C}$ a 4,0 $\mathrm{m}$ de altura (cerca de $19,6 \%$ ).

O perfil das 16h45 min (Fig. 6A e B) representa o período após o encerramento da nebulização e o fechamento das cortinas. Nesse horário, tem-se uma distribuição mais homogênea de temperatura em todo o perfil, porém com valores médios de $41,5^{\circ} \mathrm{C}$ no ambiente protegido onde houve nebulização e ventilação natural e $42,1{ }^{\circ} \mathrm{C}$ no ambiente controle, evidenciando o efeito de redução de temperatura do ar pela nebulização mesmo após o seu encerramento. 
Analisando-se a Figura 6A observa-se que com a abertura da cortina zenital (11h30 min) e abertura da cortina lateral (12h15 min) o perfil vertical de temperatura do ar não teve distribuição crescente (ou decrescente) com a altura, conforme observado por Buriol et al. (1993) em ambiente protegido com tomate e alface sem abertura para saída de ar no teto. Após o início da nebulização (13h30 min e 16h45 min) e antes da abertura das cortinas laterais e zenital, observou-se um perfil de distribuição de temperatura crescente com a altura em relação ao solo. Entretanto, Verheye \& Verlodt (1990) comparando 3 diferentes sistemas de ventilação estática no sul da Tunísia concluíram que houve melhor uniformidade de distribuição vertical de temperatura do ar em ambiente protegido equipado com abertura no teto. A influência de ventos poderia ter influenciado esta distribuição vertical de temperatura do ar gerando pontos de maior temperatura do ar alternado com pontos de menor temperatura ao longo do perfil.

A Figura 7 apresenta as isotermas a $0,5 \mathrm{~m}$ de altura em relação ao nível do solo no dia 1 de dezembro de 1999 para o ambiente protegido com nebulização e abertura de cortinas laterais e zenitais e o ambiente protegido controle para diferentes horários.
A.

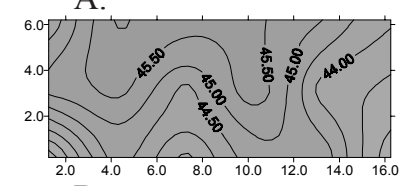

B.

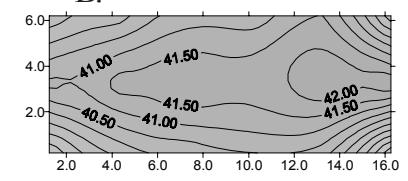

C.

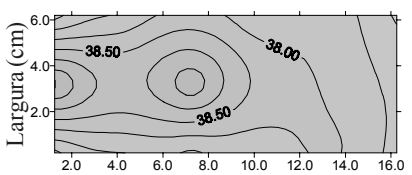

D.

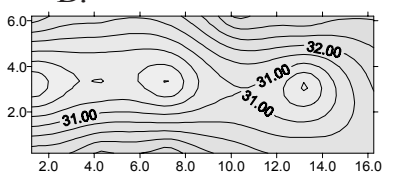

E.

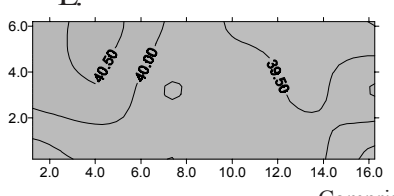

Comprimento $(\mathrm{m})$
F.

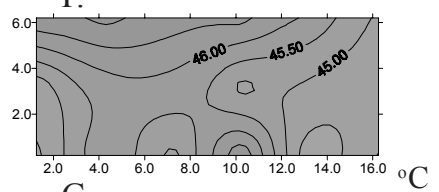

G.

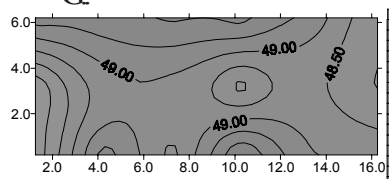

H.

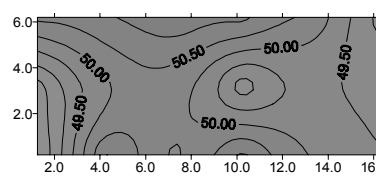

I.

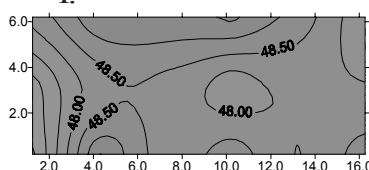

J.

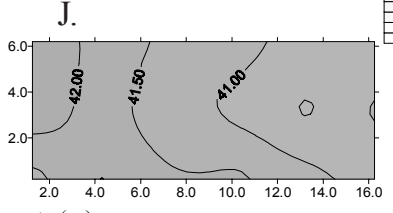

Figura 7. Distribuição de temperatura do ar no ambiente protegido com nebulização e abertura de cortinas laterais e zenital (A, B, $\mathrm{C}, \mathrm{D}$ e E) e o ambiente protegido controle ( $\mathrm{F}, \mathrm{G}, \mathrm{H}, \mathrm{I} \mathrm{e} \mathrm{J})$ para os horários das $10 \mathrm{~h} 30 \mathrm{~min}(\mathrm{Ae} \mathrm{F}), 11 \mathrm{~h} 30 \mathrm{~min}(\mathrm{~B} \mathrm{e} \mathrm{G}), 12 \mathrm{~h} 15 \mathrm{~min}(\mathrm{C}$ e H), $13 \mathrm{~h} 30 \mathrm{~min}(\mathrm{D}$ e I ) e $16 \mathrm{~h} 45 \mathrm{~min}$ (E e J) à 0,5 de altura em relação ao nível do solo, no dia 1/12/1999

Às 10h30 min (Fig. 7A e F) ocorreu uniformização de temperatura do ar nos ambientes protegidos, não apresentando grande amplitude de variação. Antes do início do manejo do ambiente protegido as temperaturas médias do ar foram de $45 \mathrm{e}$ $45,5^{\circ} \mathrm{C}$ para o ambiente protegido com nebulização e ventilação natural e para o ambiente protegido controle, respectivamente.

Com a abertura da cortina zenital no ambiente protegido às $11 \mathrm{~h} 30$ min (Fig. 7B) houve redução da temperatura do ar no ambiente, porém, com a formação de uma zona de temperatura mais elevada no centro devido à saída de ar quente pela janela zenital e entrada de ar externo pelas laterais, mesmo estando com as cortinas laterais fechadas, variando a temperatura do ar de 40 a $41,5{ }^{\circ} \mathrm{C}$, com temperatura média de $40,8{ }^{\circ} \mathrm{C}$. No ambiente protegido controle (Fig. $7 \mathrm{G}$ ) ocorreu elevação da temperatura do ar com distribuição de temperatura variando de 48,5 a $49,5^{\circ} \mathrm{C}$, com temperatura média de $48,7^{\circ} \mathrm{C}$. A redução da temperatura do ar foi de $16,2 \%$. A abertura das janelas laterais a 1,0 $\mathrm{m}$ de altura em relação ao nível do solo às $12 \mathrm{~h} 15 \mathrm{~min}$, proporcionou redução da temperatura do ar do ambiente protegido, conforme pode ser visualizado na Figura 7C. Constatou-se a formação de um gradiente de temperatura mais acentuado com temperaturas menores nas laterais do ambiente protegido aumentando em direção a área central do mesmo. As temperaturas do ar variaram de 38,5 a $39,5^{\circ} \mathrm{C}$, com temperatura média de $38,5^{\circ} \mathrm{C}$.

No ambiente protegido controle (Fig. 7H) deu-se elevação da temperatura do ar, porém com temperatura do ar variando de cerca de 48 a $51^{\circ} \mathrm{C}$ e com temperatura média de $49,8^{\circ} \mathrm{C}$. Para esta situação, a redução das temperaturas do ar do ambiente protegido com cortinas zenitais e laterais abertas comparadas com as temperaturas do ambiente controle, foi de $11,3{ }^{\circ} \mathrm{C}$ $(22,7 \%)$.

$\mathrm{O}$ acionamento da nebulização no ambiente protegido proporcionou reduções de temperatura do ar e inversão no gradiente de temperatura do ar no ambiente protegido, ficando a zona central do ambiente com temperaturas mais baixas que nas laterais (Fig. 7D). As isotermas divergem do centro e longitudinalmente no ambiente protegido. No ambiente protegido controle a distribuição de temperatura do ar manteve a mesma homogeneidade de distribuição, porque as cortinas estavam fechadas, ficando quase sem a influência do vento, porém com temperaturas mais elevadas (Fig. 7I). As temperaturas médias do ambiente protegido com cortinas abertas e nebulização e do ambiente controle foram de 31,8 e $48,2^{\circ} \mathrm{C}$, respectivamente. Esse manejo representou redução de $16,4^{\circ} \mathrm{C}$, ou seja, $34 \%$.

A Figura 7E e 7J mostra o perfil de distribuição de temperatura do ar no ambiente após o término da nebulização e após o fechamento das cortinas. A distribuição de temperatura do ar no ambiente protegido nebulizado (Fig. 7E) encontra-se com temperaturas inferiores a do ambiente protegido controle (Fig. 7J) indicando a influência da nebulização e ventilação natural do ambiente na redução da temperatura do ar e seu efeito após a interrupção. A temperatura média do ar no ambiente protegido com abertura de cortinas e nebulização foi de $39,7^{\circ} \mathrm{C}$, enquanto no ambiente controle foi de $41,3{ }^{\circ} \mathrm{C}$. Após a interrupção da nebulização e ventilação natural ocorreu elevação da temperatura do ar do ambiente protegido. A distribuição da temperatura do ar nos dois ambientes protegidos mostra-se bastante homogênea variando muito pouco ao longo de toda a extensão do ambiente. A abertura das cortinas laterais e zenitais proporcionou isotermas nas quais se observa que a temperatura do ar mais elevada ficou no centro do ambiente protegido. Com o início da nebulização ocorreu fato inverso, com temperaturas menores no centro devido ao alcance dos nebulizadores. 
Na Figura 8 são apresentadas as isotermas a 2,0 $\mathrm{m}$ de altura em relação ao nível do solo no dia 1/12/1999 para o ambiente protegido com nebulização e abertura de cortinas laterais e zenitais e o ambiente protegido controle para diferentes horários.

A.

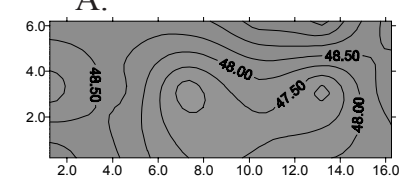

B.

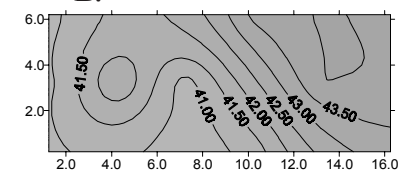

C.

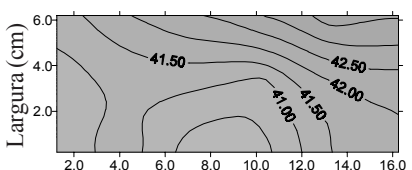

D.

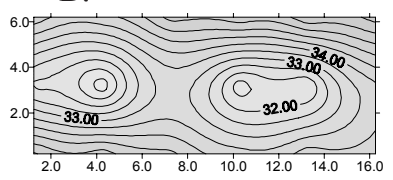

E.

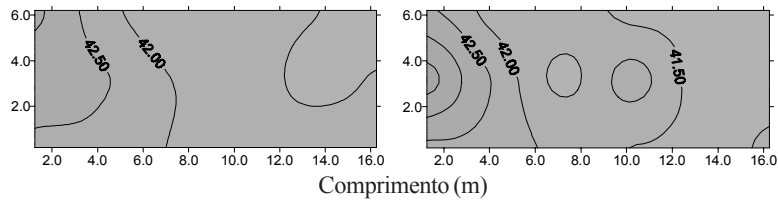

Figura 8. Distribuição de temperatura do ar no ambiente protegido com nebulização e abertura de cortinas laterais e zenital (A, B, $\mathrm{C}, \mathrm{D}$ e E) e o ambiente protegido controle (F, G, H, I e J ) para os horários das $10 \mathrm{~h} 30 \mathrm{~min}(\mathrm{AeF}), 11 \mathrm{~h} 30 \mathrm{~min}(\mathrm{~B} \mathrm{e} \mathrm{G}), 12 \mathrm{~h} 15 \mathrm{~min}(\mathrm{C}$ e H), $13 \mathrm{~h} 30 \mathrm{~min}(\mathrm{De}$ I) e $16 \mathrm{~h} 45 \mathrm{~min}$ (E e J) à 2,0 $\mathrm{m}$ de altura em relação ao nível do solo, no dia 1/12/1999

A 2,0 m de altura em relação ao nível do solo tem-se praticamente a mesma situação ocorrida a $0,5 \mathrm{~m}$, porém com temperaturas mais elevadas. Entretanto, nesta altura não se verificou a formação de zonas de temperaturas mais elevadas no centro do ambiente protegido com cortinas zenitais e laterais abertas (Fig. $8 \mathrm{~B} \mathrm{e} \mathrm{C}$ ) como ocorreu a $0,5 \mathrm{~m}$ de altura em relação ao nível do solo (Fig. 7B e C).

A temperatura do ar no ambiente protegido com nebulização e ventilação natural às $10 \mathrm{~h} 30 \mathrm{~min}$ (Fig. $8 \mathrm{~A}$ ) e no ambiente protegido controle (Fig. $8 \mathrm{~F}$ ) variou de 47 a $49^{\circ} \mathrm{C}$ com médias de temperatura do ar de 48,3 e $47,8^{\circ} \mathrm{C}$, respectivamente. Às $11 \mathrm{~h} 30 \mathrm{~min}$ a variação foi de 41 a $44{ }^{\circ} \mathrm{C}$ no ambiente protegido com a abertura da janela zenital (Fig. 8B) e de 49 a $51{ }^{\circ} \mathrm{C}$ no ambiente protegido controle (Fig. 8G) com médias de $42,3 \mathrm{e} 50,2{ }^{\circ} \mathrm{C}$, respectivamente, reduzindo a temperatura em $15,7 \%$.

Às $12 \mathrm{~h} 15 \mathrm{~min}$ a temperatura do ar no ambiente protegido com abertura de cortinas zenitais e laterais (Fig. 8C) variou de 40,5 a $43^{\circ} \mathrm{C}$ e no ambiente protegido controle (Fig. $8 \mathrm{H}$ ) de 50 a $51,5{ }^{\circ} \mathrm{C}$, com médias de temperatura de 41,5 e $50,9^{\circ} \mathrm{C}$, respectivamente (cerca de $18,5 \%$ de redução de temperatura do ar do ambiente protegido com as cortinas abertas, em comparação com o ambiente protegido controle).

Às $13 \mathrm{~h} 30 \mathrm{~min}$, com a nebulização e as cortinas abertas (Fig. 8D), verificou-se formação de uma zona central do ambiente com temperaturas mais baixas que nas laterais. As isotermas divergem do centro e longitudinalmente no ambiente protegido. No ambiente protegido controle a distribuição de temperatura do ar manteve a mesma homogeneidade de distribuição, porque as cortina estavam fechadas, ficando quase sem a influência do vento, porém com temperaturas mais elevadas (Fig. 8I). As temperaturas médias do ambiente protegido com cortinas abertas e nebulização e do ambiente controle foram de 34,1 e $49,1^{\circ} \mathrm{C}$, respectivamente. Este manejo representou uma redução de $15,0^{\circ} \mathrm{C}$, ou seja, $30,5 \%$.

Às $16 \mathrm{~h} 45 \mathrm{~min}$, após o fechamento das cortinas laterais e zenitais, houve maior uniformidade de distribuição de temperatura do ar nos dois ambientes protegidos com temperaturas variando de 41,5 a $42,5^{\circ} \mathrm{C}$ nos dois ambientes e temperaturas médias do ar de cerca $41,8{ }^{\circ} \mathrm{C}$ no ambiente protegido manejado e $41,9{ }^{\circ} \mathrm{C}$ no ambiente protegido controle.

$\mathrm{O}$ uso de um método de redução da temperatura do ar em ambientes protegidos pode não ser suficiente para reduzir a temperatura do ar a um nível aceitável pelas culturas em períodos de temperaturas elevadas. A combinação dos métodos permitiu uma redução da temperatura do ar mais eficiente. De acordo com Montero \& Antón (1994) e Andriolo (1999) com a combinação inteligente de diferentes sistemas de resfriamento, como a nebulização e a ventilação natural, pode-se conseguir um clima adequado durante meses mais quentes.

\section{CONCLUSÕES}

1. A nebulização e a ventilação natural em ambientes protegidos proporcionaram a redução de temperatura do ar em cerca de $17^{\circ} \mathrm{C}$.

2. A análise da distribuição da temperatura do ar por meio de isotermas permitiu uma visão global instantânea do processo de redução de temperatura do ar.

3. A distribuição de temperatura do ar no ambiente protegido não é homogênea e a escolha do local ideal para instalação de sensores e equipamentos é muito importante para a obtenção dos dados mais representativos das condições micrometeorológicas nestes ambientes.

\section{LITERATURA CITADA}

Al-Jamal, K. Greenhouse cooling in hot countries. Energy, v.19, n.11,p.1187-1192, 1994.

Andriolo, J.L. Fisiologia das culturas protegidas. Santa Maria: Ed. da UFSM, 1999. 142p.

Baeten, S.; Verlodt, H.; El Fahen, S.; Harbaoui, Y. Visualization of temperature distribution in PE greenhouses with static aeration. Acta Horticulturae, Karlsruhe - Germany, v.170, p.173-184, 1985. 
Buriol, G.A.; Heldwein, A.B.; Streck, N.A.; Schneider, F.M.; Estefanel, V.; Dalmago, G.A. Gradiente vertical de temperatura do ar no interior de estufas plásticas. In: Congresso Brasileiro de Agrometeorologia, 10, 1997, Piracicaba. Anais... Piracicaba: Sociedade Brasileira de Agrometeorologia. p.471-472, 1997.

Fang, W. Greenhouse cooling in subtropical regions. Acta Horticulturae, Kyoto-Japan, v.399, p.37-48, 1995.

Montero, J.I.; Antón, A. Greenhouse cooling during warm periods. Acta Horticulturae, Baltimore-USA, v.357, p.49-61, 1994.

Montero, J.I.; Antón, A.; Biel, C.; Franquet, A. Cooling of greenhouse with compressed air fogging nozzles. Acta Horticulturae, Montpellier - France, v.281, p.199-209, 1990.
Oca, J.; Montero, J.I.; Antón, A.; Crespo, D. A method for studying natural ventilation by thermal effects in a tunnel greenhouse using laboratory-scale models. Journal of Agricultural Engenering Resource, New York, v.72, p.93-104, 1999.

Triki, J.; Verlodt, H.; Baeten, S. Influence de differents systemes d'aeration sur la distribution des temperatures sous serre polyethylene. Acta Horticulturae, The Hague, v.154, p.241-248, 1984.

Verheye, Ph.; Verlodt, H. Comparison of different systems for static ventilation of hemispheric plastic greenhouses. Acta Horticulturae, Montpellier - France, v.281, p.183-197, 1990. 